
\title{
25 Research Square \\ Potential triggers of atrial fibrillation in type 2 diabetes mellitus
}

\author{
Zulfiya Mirzarakhimova \\ Heart Team Association
}

Bakhodir Narziev ( $\square$ akacanmore92@gmail.com )

Heart Team Association https://orcid.org/0000-0001-5880-9310

Akmal Yakubov

Heart Team Association

Oybek Salaev

Heart Team Association

\section{Ramesh Hamraev}

Heart Team Association

\begin{abstract}
Aliyor Ganiev
Heart Team Association

Sukhrob Tursunov

Heart Team Association
\end{abstract}

Rasulbek Jumaniyozov

Heart Team Association

Sardorkhon Sultankhonov

Heart Team Association

\section{Original investigation}

Keywords: continuous glucose measurement, diabetes mellitus, atrial fibrillation, continuous ECG monitoring, hypoglycemia, fasting plasma insulin, insulin resistance

Posted Date: April 13th, 2021

DOl: https://doi.org/10.21203/rs.3.rs-408113/v1

License: (c) (1) This work is licensed under a Creative Commons Attribution 4.0 International License. Read Full License 


\section{Abstract}

\section{Introduction.}

Atrial fibrillation is an irregular heartbeat that accelerates to form blood clots in the chambers of the heart and leads to stroke, heart failure, and other cardiovascular complications. Diabetes mellitus itself has been identified as a risk factor for atrial fibrillation, but the association between them is unclear.

\section{Material and methods.}

We analyzed 70 patients with type 2 insulin non-dependent diabetes mellitus. All patients were examined in parallel continuous glucose (CGM) and ECG for 14 days. The study population divided into documented atrial fibrillation (AF group, $n=16$ ) and without atrial fibrillation (non-AF group, $n=54$ ) groups. We assessed the relationship between hypoglycemia, fasting plasma insulin, insulin resistance using the homeostatic model assessment (HOMA-IR) equation, and the incidence of atrial fibrillation.

\section{Results.}

We found a total of 46 episodes of documented atrial fibrillation (AF be defined as an arrhythmia lasting $\geq 30$ seconds) lasted on the whole 596.9 minute, which was the most significant by the number (2.87 \pm 2.05 per patient, $p<0.0001)$ or the time $(31.31 \pm 16.57$ min per patient, $p<0.0001)$. We also compared the incident rate of different types of atrial premature complexes between two groups. We found a maximum of $642.6 \pm 567.2$ single PACs per patient in the AF group, compared to $84.6 \pm 87.9, p=0.002$. Despite this, there were significant differences by the following parameters: couplet PACs $(p=0.0015)$ and triplet or $>3$ PACs $(p=0.0007)$. Over 14 days, a total of 263 hypoglycemic episodes or 5135 min hypoglycemic time were detected, the average number and time of hypoglycemic episodes were $8.0 \pm 4.94$ per person and $137.0 \pm 63.17 \mathrm{~min}$ in AF group, and $2.5 \pm 4.64$ per person $(p=0.0001), 54.5 \pm 67.3 \mathrm{~min}(p=0.004)$ in the non-AF group. There was a statistically significant $(p<0.0001)$ association between FPI and incident AF, more exactly, the mean level of FPI was $31 \pm 6.1 \mathrm{mIU} / \mathrm{L}$ in the AF group, whereas was $11.3 \pm 4.07$ in the non-AF group. When we measured the HOMA-IR index by using the homeostasis model, we found significant differences between AF and non-AF groups $(11.2 \pm 3.88 \mathrm{mmol} / \mathrm{l}$ vs. $4.3 \pm 1.66 \mathrm{mmol} / \mathrm{l}, \mathrm{p}<$ 0.0001).

\section{Conclusion.}

The parallel recording of continuous glucose and ECG are necessary to evaluate hypoglycemia-related atrial fibrillation in type 2 diabetes mellitus. Elevated fasting plasma insulin, as well as insulin resistance, are important predictors of atrial fibrillation development, but it needs further studies. 


\section{Introduction}

Atrial fibrillation (AF) is the most common arrhythmia in the general population, with an estimated lifetime risk of $25 \%$ worldwide [1]. Clinically, AF is important due to its association with increased risk of stroke, heart failure, myocardial infarction, and total mortality [2]. Diabetes itself has been identified as a risk factor for AF, increasing the risk of new-onset AF by 34-40\% [3]. Atrial structural, electrical, and electromechanical remodeling with multiple metabolic defects has been suggested as a mechanism for the relationship between diabetes and AF [4].

A focus has been placed on risk factors responsible for AF development and recurrence to decrease the burden and improve outcomes of diabetic patients. The well-known risk factors for AF include age, male gender, hypertension, and heart disease [5]. However, the established risk factors for AF can only account for approximately half of the AF cases in the population [5-7]. Thus, new approaches to screening risk factors are needed. A recent meta-analysis has shown that, diabetes is a risk factor for AF [3], but controversy remains regarding complex mechanism. There is some evidence that hypoglycemia increases risk $[8,9]$.

There have been occasional case reports of supraventricular and ventricular arrhythmias associated with hypoglycemia. Transient AF is the most common among supraventricular arrhythmias [10]. There have also been several comparative analyzes of the incidence of bradycardia in severe hypoglycemia in patients with diabetes versus none [11]. Moreover, many episodes with critical low glucose levels may be asymptomatic, and arrhythmias will be unrecognized during sleep, it is still difficult to document these events in parallel. Nowadays, in cardioendocrinology, there is a technique of the so-called parallel continuous glucose (CGM) and ECG monitoring. CGM has an invasive sensor that sends signals and data to a display device, after measuring glucose in interstitial fluid. It is possible to register all the parameters of the electrical cardiac activity, when the patient is in a state of hypoglycemia.

In addition to hypoglycemia, fasting plasma insulin (FPI) also is a risk factor for cardiovascular disease [12] and overall mortality [13]. It is, however, not clear whether FPI or insulin resistance are risk factors for AF. A significant association between insulin resistance and AF was not found in the Framingham cohort [14], and in the ARIC study, like the previous one, there was no positive relation between FPI and the risk of AF [7]. On the contrary, several studies have shown that metabolic syndrome, wherein insulin resistance is a key component, is related to the incidence of AF [15-19]. Thus, the role of FPI in the epidemiology of AF remains controversial. Accordingly, the question arises: how does insulin work in the body? Insulin effects on the vasculature through specific endothelial insulin receptors. The relationship between insulin and the endothelium is sophisticated and has been shown to vary according to whether the subject is insulin resistant or not $[20,21]$. In the case of normal insulin sensitivity, the endothelium lowers blood pressure and increases blood flow [21] through the release of nitric oxide. However, in the insulin-resistant endothelium, the effect seems to be reversed, insulin causes vasoconstriction instead and subsequently elevates blood pressure [20]. Therefore, as hemodynamic factors are significant risk factors for AF the 
relationship between insulin and AF could vary according to the individual's degree of insulin sensitivity and glycemia.

This observational research aimed to study the relationship between potential risk factors as hypoglycemia, $\mathrm{FPI}$, or insulin resistance and the rate incidence of atrial fibrillation in type 2 diabetes. Therefore, we examined the level of FPI and measured insulin resistance by the homeostatic model of insulin resistance (HOMA-IR) (22) and used continuous glucose and ECG monitoring in parallel for 14 days in patients with type 2 diabetes, who had been treated only with oral hypoglycemic agents.

\section{Materials And Methods}

Seventy patients with insulin non-dependent type 2 diabetes mellitus for at least 10 years were recruited from public and private medical centers of Tashkent, Uzbekistan. The majority of patients had a history of cardiovascular disease (coronary artery disease (CAD) or peripheral vascular or cerebrovascular disease) and/or additional cardiovascular risk factors: hypertension, current smoking, and obesity. Inclusion criteria were: insulin non-dependent type 2 diabetes without previously documented AF; age 5080 years; stable CAD; chronic heart failure (CHF) I-III functional classes (FC) according to New York Heart Association (NYHA); and chronic kidney disease (CKD) 1-3 stage (glomerular filtration rate (GFR) $>30$ $\mathrm{ml} / \mathrm{min} / 1.73 \mathrm{~m} 2$ ). Exclusion criteria were: type 1 diabetes or insulin dependent type 2 diabetes; documented AF; valvular pathology; acute coronary syndrome or acute myocardial infarction; CHF IV FC by NYHA; CKD stage 4-5 (GFR <30 ml/min/1.73 m2); thyroid gland pathology; ECG changes like atrioventricular block II and III degree, or implanted pacemaker or defibrillator; and treatment with antiarrhythmic drugs besides b-blockers and calcium channel blockers. Patients were excluded from the study if a blood sample, obtained at baseline, showed electrolyte imbalance.

We recorded interstitial glucose (IG) concentrations with CGM in the interstitial fluid of the subcutaneous fat, which, with stable glycemia, corresponds to the level of capillary glucose (Gross TM et al., 2000) for 14 days. Continuous monitoring of glycemia in patients was carried out using a portable CGM system Freestyle Libre from Abbot (USA), which consists of three main parts: a sensor, a monitor, and a data transmission device to a computer. The principle of monitoring is based on the glucose oxidase method. The monitor samples waveforms every 10 seconds and records the average waveform every 1 minute. After the end of the study, the data obtained were loaded into a personal computer and processed using the Solution ${ }^{\mathrm{Tm}}$ Software MMT-7310 version $3.0 \mathrm{C}$. The limits of glucose measurement with this device are from $39,6 \mathrm{mg} / \mathrm{dL}$ to $399,6 \mathrm{mg} / \mathrm{dL}$. The period of normoglycemia in a study using CGM was understood as a glucose level from 70 to $180 \mathrm{mg} / \mathrm{dL}$ in time in range $(T I R)>70 \%$ and a glucose level $<70 \mathrm{mg} / \mathrm{dL}$ in time below range $(\mathrm{TBR})<4 \%$, which is recommended in International Consensus on the Use of the Continuous Glucose Monitoring [23]. Hypoglycemia was defined as $\mathrm{IG}<70 \mathrm{mg} / \mathrm{dL}$ in $\mathrm{TBR}>4 \%$, and hyperglycemia was defined as $I G>180 \mathrm{mg} / \mathrm{dL}$ in time above range (TAR) $>30 \%$. The first reading of $I G<70 \mathrm{mg} / \mathrm{dL}$ marked the start of the hypoglycemic episode, and the first reading of IG $>70 \mathrm{mg} / \mathrm{dL}$ signified the end of the episode. 
We used The 2-lead ambulatory continuous ECG system the Twin-Trac SRA + V2 for continuous ECG monitoring, data were analyzed with the SR-Medizinelektronik system (Stuttgart, Germany). The software automatically detected arrhythmia including bradycardia, single premature atrial (PACs) or ventricular (PVCs) complexes, complex beats (bigeminy, trigeminy, couplet, triplet, supra- or ventricular tachycardia), and atrial fibrillation. All identified arrhythmic events were manually checked. Investigators were not aware of the glucose values during the arrhythmia analysis. All parameters were brought to 24 hours to synchronize the readings of CGM and ECG monitoring for statistical analysis. Patients were instructed to notice all symptoms of hypoglycemia and arrhythmias with date and time in a predefined protocol during CGM and ECG monitoring.

Height $(\mathrm{m})$ was measured using a stationary stadiometer; weight (kg) was measured using an electronic scale. Systolic blood pressure (SBP) $(\mathrm{mmHg})$ was measured thrice after 15 min of supine rest, using a sphygmomanometer with a modifiable cuff. Blood samples were collected with strict fasting at each examination. Standardized insulin levels were measured in plasma as immunoreactive insulin at 1 timepoint. Insulin resistance was defined by previously validated homeostasis model assessment of insulin resistance (HOMA-IR), assessed by the formula = (fasting plasma insulin [mU/L])x(fasting plasma glucose [mmol/L])/22.5 [24].

\section{Statistical analysis}

Statistical analyses were performed using STATISTA version 10.0 (TIBCO, USA). Descriptive characteristics were presented as mean \pm SD or $95 \%$ confidence interval. Data were also interpreted as numbers and as a frequency percentage (\%). Unpaired Student's t-test for two groups was applied. The confidence intervals $(95 \% \mathrm{Cl})$ are calculated using the pooled standard deviation. A value of $\mathrm{P}>0.05$ was considered to be significant. The odds ratios (ORs) were used to describe the risk of different comorbidities in AF patients compared with non-AF patients. The model estimated ORs with 95\% confidence intervals for each specified group.

\section{Results}

From January 1, 2020, to December 31, 2020, 70 patients with type 2 insulin non-dependent diabetes mellitus who had not been previously documented AF were included in this study. The majority of patients were aged from 55 to 64 (56\%), only $11 \%$ of patients were aged $70-74$. The study included almost similar numbers of patients by gender (ratio 1.2:1). Besides, the number of patients on the duration of diabetes was different, for example, it was 8 years in 12 patients and 1 year only in 4 . All other demographic characteristics are described in detail in Diagram 1.

Associated comorbidities of AF and type 2 diabetes mellitus in our patients were: coronary artery disease (65\%); post-infarction cardiosclerosis (20\%); arterial hypertension (66.2\%); chronic heart failure (75\%); and chronic kidney disease (81.3\%). In the odds ratio analysis, significant heterogeneities were not observed by the proportion of comorbidities, as shown in Diagram 2 . Of 70 patients, $64 \%$ were received beta- 
blockers; $68 \%$ angiotensin-converting enzyme inhibitors; $65.7 \%$ mineralocorticoid receptors inhibitors; $4 \%$ digoxin; $17 \%$ calcium antagonists; $7 \%$ loop diuretics; $85 \%$ aspirin; $1,4 \%$ oral anticoagulant therapy; and $11 \%$ were on dual antithrombotics. From oral hypoglycemic agents: $32.8 \%$ were received sulfonylureas; $78.5 \%$ biguanides; $20 \%$ glucagon-like peptide-1 receptor agonists; $17.7 \%$ sodium-glucose transport protein 2 inhibitors; $41.4 \%$ dipeptidyl peptidase 4 inhibitors.

A parallel ECG and glucose monitoring for 14 days were obtained from 70 patients with type 2 diabetes. We divided the whole study population into 2 groups after receiving CGM and continuous ECG monitoring results. In the first group, we included patients with episodes of documented atrial fibrillation $(n=16)$, in another, patients without atrial fibrillation $(n=54)$. Patients were similar in age, body mass index $(B M I)$, blood chemistry, glycated hemoglobin (HbA1c), blood pressure, parameters of lipid metabolism, renal function, and echocardiography, but there was a significant difference in potassium level $(p=0.009)$ as shown in Table 1.

A total of 46 episodes of documented atrial fibrillation (AF be defined as an arrhythmia lasting $\geq 30$ seconds) lasted on the whole 596.9 minute, which was the most significant by the number $(2.87 \pm 2.05$ per patient, $p<0.0001)$ or the time $(31.31 \pm 16.57$ min per patient, $p<0.0001)$ were detected. The incident rate of various types of atrial premature complexes between two groups were also compared. We found a maximum of $642.6 \pm 567.2$ single PACs per patient in the AF group, compared to $84.6 \pm 87.9, p=0.002$. Despite this, there were significant differences by the following parameters, shown in Table 2: couplet PACs $(p=0.0015)$ and triplet or $>3$ PACs $(p=0.0007)$. QTc interval was also similar in both groups $(p=$ 0.317). SDNN is a marker of cardiac autonomic neuropathy that was not significantly different between the AF group versus the non-AF group $(p=0.245)$ as shown in Table 2.

The data received from CGM for 14 days showed that only 38 patients out of 70 were in TIR $>70 \%$ (glucose value between 70 and $180 \mathrm{mg} / \mathrm{dL}$ ) that, means normoglycemia, out of them, 7 patients were in the AF group, and 23 were in another (OR 0,980, $\mathrm{Cl} 95 \%$ [3.03-0.317], $\mathrm{p}=0.973$ ). Moreover, $56 \%$ patients of AF group and $53.7 \%$ patients of non-AF group were in TAR $>30 \%$ (glucose value above $180 \mathrm{mg} / \mathrm{dL}$ ) (OR 1.019, $\mathrm{Cl} 95 \%$ [3.15-0.33], $\mathrm{p}=0.973$ ). The most significant result was the number of patients, being in TBR > 4\% (glucose value below $70 \mathrm{mg} / \mathrm{dL}$ ), 14 (87.5\%) in first and only $11(20.3 \%$ ) in second group (OR 28.63, Cl 95\% [144.94-5.65], $p=0.0001)$.

Mean intestinal glucose, as well as maximum intestinal glucose parameters, were not different between the AF group and non-AF group (Table 3); however, the minimum intestinal glucose was significantly lower in the AF group compared to their counterparts ( $52.8 \pm 16.4$ vs $79.1 \pm 32.59$, respectively, $p=0,003$ ). Over 14 days, a total of 263 hypoglycemic episodes or 5135 min hypoglycemic times were detected, the average number and time of hypoglycemic episodes were $8.0 \pm 4.94$ per patient and $137.0 \pm 63.17 \mathrm{~min}$ in AF group, and $2.5 \pm 4.64$ per patient $(p=0.0001), 54.5 \pm 67.3 \mathrm{~min}(p=0.004)$ in the non-AF group. There were no significant differences in the number of daily scans and the percentage of data analysis between both groups (Table 3 ). 
A statistically significant association between fasting plasma insulin $(p<0.0001)$ and incident AF was found. More exactly, the mean level of FPI was $31 \pm 6.1 \mathrm{mlU} / \mathrm{L}$ in the AF group, whereas was $11.3 \pm 4.07$ in the non-AF group. When we measured the HOMA-IR index by using the homeostasis model, we observed a significant difference between AF and non-AF groups $(11.2 \pm 3.88 \mathrm{mmol} / \mathrm{l}$ vs. $4.3 \pm 1.66 \mathrm{mmol} / \mathrm{l}, \mathrm{p}<$ 0.0001).

Thus, we detected a statistically significant difference between atrial fibrillation and three potential factors as hypoglycemia, fasting plasma insulin, and insulin resistance in our observational research. In more detail, the association between atrial fibrillation and FPI or insulin resistance was more significant than hypoglycemia.

\section{Discussion}

In this study, patients baseline characteristics, cardiovascular disease, and comorbidity status were similar between type 2 diabetic patients who had atrial fibrillation versus none. Yet, our observational data showed an increase in atrial ectopic activity that was coincident with hypoglycemic episodes, increasing FPI or HOMA-IR index.

In the AF group, serum potassium level was statistically significantly lower than the non-AF group. We associated a decrease in the level of potassium in the first group with an increase in the level of insulin, as they write in the literature, insulin shifts potassium into cells by stimulating the activity of $\mathrm{Na}+\mathrm{H}+$ antiporter on the cell membrane, promoting the entry of sodium into cells, which leads to activation of the $\mathrm{Na}+-\mathrm{K}+$ ATPase, causing an electrogenic influx of potassium [25], thus, the level of potassium decreases.

A temporary relation between severe hypoglycemia, acute cardiovascular events and sudden death has been demonstrated in some case series [26,27]. In one study, continuous glucose measurements and continuous ECG monitoring were performed simultaneously in patients with type 2 diabetes and established coronary artery disease, 54 episodes of hypoglycemia (blood glucose level $<70 \mathrm{mg} / \mathrm{dL}$ ) were identified, 10 of which (18,5\%) were accompanied by anginal pain [28]. The multiple case reports of cardiac arrhythmias triggered by spontaneous hypoglycemia [27] underline the clinical relevance of the association, particularly since ethical considerations restrict experimental studies in this area. Those reported range from severe sinus bradycardia (which can progress to asystole) and atrial fibrillation to ventricular tachycardia. This illustrates the complexity of demonstrating that a serious cardiac event has been provoked by acute hypoglycemia in a diabetic patient since simultaneous glucose and ECG monitoring is rarely possible in clinical practice. In our study, we referred to this issue with emphasis and believe that this is crucial method for patients belonging to high-risk groups.

Our investigations of the parallel recording of CGM and ECG for 14 days reveal a high incidence of both episodes of low IG ( $<70 \mathrm{mg} / \mathrm{dL}$ ) levels and atrial arrhythmias in type 2 diabetes who were treated with only oral hypoglycemic agents. Although, the ACCORD and ADVANCE studies showed that, severe hypoglycemia did not associate with cardiovascular events and mortality [29, 30]. Thus, the question was whether hypoglycemia is harmful? We can answer this question based on the results of our research. We 
detected a high incidence of hypoglycemia (time below range $<70 \mathrm{mg} / \mathrm{dL}(>4 \%)$ ) in the AF group (14 out of 16). It is demonstrated that, in our study, hypoglycemia is associated with an increased risk of atrial fibrillation in patients with type 2 diabetes. Otherwise, the non-AF group consisted of 11 patients (20.3\%) in time below range $<70 \mathrm{mg} / \mathrm{dL}(>4 \%)$, but no atrial fibrillation was detected. Moreover, both groups were almost similar in terms of the content of patients with intestinal glucose levels in time in range 70-180 $\mathrm{mg} / \mathrm{dL}(>70 \%)(43.75 \%$ vs $42.6 \%$, respectively) and time above range $>180 \mathrm{mg} / \mathrm{dL}(>30 \%)(56.25 \% \mathrm{vs}$ $58.4 \%$, respectively). Our study suggests that hypoglycemia is a proarrhythmic condition with a high risk of not only atrial fibrillation but atrial premature complexes as asingle, couplet, and triplet or more than 3 complexes.

The relationship between level of FPI or insulin resistance and incident AF has varied in prior studies [7, 31]. The results of the present study differ from the results of the ARIC study, which found no significant association between fasting insulin and incident AF [7]. In the ARIC study, the mean age was 57 years; almost as in the present study at baseline. The same argument holds for the Framingham Heart Study which reported no relationship between insulin resistance and incident AF in subjects with a mean age of 59 years and a mean BMl of $27.4 \mathrm{~kg} / \mathrm{m} 2$. The researchers examined data of participants from the fifth cycle (1991 to 1994) and the seventh cycle (1998-2001). Among approximately 4,600 patients, the rate of incident atrial fibrillation over 10 years was $5.8 \%$ in those with insulin resistance and $6.1 \%$ in those without insulin resistance (HR 1.03, 95\% $\mathrm{Cl} 0.72$ to 1.46) [31]. On the contrary, compared to the above studies, we found positive relations, that evaluated FPI and insulin resistance, based on HOMA-IR, was associated with an increased risk of incident AF among type 2 diabetes mellitus. We hypothesize that, hyperinsulinemia is often accompanied by high glucose variability and in combination with hyperglycemia may pose a higher risk, as hyperglycemia develops when insulin levels can no longer sufficiently lower glucose levels. Insulin itself is a recognized growth factor and has been shown to promote cardiac structural remodeling (32-34). Hyperinsulinemia also leads to sodium retention (35), which potentially causing fluid retention. Furthermore, higher insulin levels activate the sympathetic nervous system (36). Insulin resistance is associated with a more pronounced response to angiotensin II, which may contribute to changes in cardiac structure [37], and structural atrial remodeling can lead to the development of atrial fibrillation.

Finally, our data suggest that AF risk associated with an increased level of FPI, insulin resistance, and hypoglycemic episodes, will need to be assessed in additional clinical research and examined concerning different outcomes.

Limitations of our study include that it was prospective, non-randomized observational study with limited sample size, due to this study does not require an estimate of sample size. Another limitation is that fasting plasma insulin collected at 1 timepoint not multiple, this does not exclude the influence of laboratory error.

\section{Conclusion}


We concluded that the parallel recording of CGM and CEM are urgently needed to evaluate the predictors of atrial fibrillation in type 2 diabetes mellitus. An increase in fasting plasma insulin levels, as well as insulin resistance, is closely related to the development of atrial fibrillation. We want to introduce a new term - insulin toxicity in the daily practice of a cardiologist as a possible risk factor for the development of atrial fibrillation, but, this requires multicenter randomized controlled studies to prove its role.

\section{Declarations}

Ethics approval and consent to participate: This study was approved by the Biomedical Research Ethics Committee of our Republic with a waiver of informed consent due to the retrospective nature of this investigation.

Consent for publication: Not applicable.

Competing interests: None of the authors had competing interests in this study.

Funding: This research did not receive any specific grant from funding agencies in the public, commercial, or not-for-profit sectors.

Contributions: $\mathrm{BN}, \mathrm{ZM}, \mathrm{AY}$, and OS collected outpatient data and contributed to the data analyses. BN prepared the manuscript. RH, RJ, ST, and SS performed biochemical evaluations and contributed to the data analyses. $\mathrm{BN}, \mathrm{AY}, \mathrm{OS}, \mathrm{RJ}$, and $\mathrm{RH}$ reviewed the manuscript. BN was the guarantor of this work, had full access to all study data, and assumed responsibility for data integrity and analytical accuracy. All authors read and approved the final manuscript.

Acknowledgements: Not applicaple.

Availability of data and materials: Not applicable.

\section{References}

1. Chugh SS, Havmoeller R, Narayanan K, Singh D, Rienstra M, Benjamin EJ, et al. Worldwide epidemiology of atrial fibrillation: a Global Burden of Disease 2010 Study. Circulation. 2014;129:837-47. [PubMed: 24345399].

2. Violi F, Soliman EZ, Pignatelli P, Pastori D. Atrial Fibrillation and Myocardial Infarction: A Systematic Review and Appraisal of Pathophysiologic Mechanisms. J Am Heart Assoc. 2016;5:e003347. [PubMed: 27208001].

3. Huxley RR, Filion KB, Konety S, Alonso A. Meta-analysis of cohort and case-control studies of type 2 diabetes mellitus and risk of atrial fibrillation. Am J Cardiol. 2011;108:56-62. [PubMed: 21529739].

4. Tadic M, Cuspidi C. Type 2 diabetes mellitus and atrial fibrillation: From mechanisms to clinical practice. Arch Cardiovasc Dis. 2015;108:269-76. [PubMed: 25858534]. 
5. Benjamin EJ, Levy D, Vaziri SM, D'Agostino RB, Belanger AJ, Wolf PA. Independent risk factors for atrial fibrillation in a population-based cohort. The Framingham Heart Study JAMA. 1994;271(11):840-4.

6. Smith JG, Platonov PG, Hedblad B, Engstrom G, Melander O. Atrial fibrillation in the Malmo Diet and Cancer study: a study of occurrence, risk factors and diagnostic validity. Eur $\mathrm{J}$ Epidemiol. 2010;25(2):95-102.

7. Huxley RR, Lopez FL, Folsom AR, Agarwal SK, Loehr LR, Soliman EZ, Maclehose R, Konety S, Alonso A. Absolute and attributable risks of atrial fibrillation in relation to optimal and borderline risk factors: the Atherosclerosis Risk in Communities (ARIC) study. Circulation. 2011;123(14):1501-8.

8. Huxley RR, Alonso A, Lopez FL, Filion KB, Agarwal SK, Loehr LR, Soliman EZ, Pankow JS, Selvin E. Type 2 diabetes, glucose homeostasis and incident atrial fibrillation: the Atherosclerosis Risk in Communities study. Heart. 2012;98(2):133-8.

9. Dublin S, Glazer NL, Smith NL, Psaty BM, Lumley T, Wiggins KL, Page RL, Heckbert SR. Diabetes mellitus, glycemic control, and risk of atrial fibrillation. J Gen Intern Med. 2010;25(8):853-8.

10. Celebi S, Celebi OO, Aydogdu S, Diker E. A peculiar medical cardioversion of atrial fibrillation with glucose infusion-a rare cause of atrial fibrillation: hypoglycemia. Am J Emerg Med. 2011;29:134.e1-3.

11. Bolognesi R, Tsialtas D, Bolognesi MG, Giumelli C. Marked sinus bradycardia and QT prolongation in a diabetic patient with severe hypoglycemia. J Diabetes Complications. 2011;25:349-51.

12. Eddy D, Schlessinger L, Kahn R, Peskin B, Schiebinger R. Relationship of insulin resistance and related metabolic variables to coronary artery disease: a mathematical analysis. Diabetes Care. 2009;32(2):361-6.

13. Nilsson P, Nilsson JA, Hedblad B, Eriksson KF, Berglund G. Hyperinsulinaemia as long-term predictor of death and ischaemic heart disease in nondiabetic men: The Malmo Preventive Project. J Intern Med. 2003;253(2):136-45.

14. Fontes JD, Lyass A, Massaro JM, Rienstra M, Dallmeier D, Schnabel RB, Wang TJ, Vasan RS, Lubitz SA, Magnani JW, Levy D, Ellinor PT, Fox CS, Benjamin EJ. Insulin resistance and atrial fibrillation (from the Framingham Heart Study). Am J Cardiol. 2012;109(1):87-90.

15. Vyssoulis G, Karpanou E, Adamopoulos D, Kyvelou SM, Tzamou V, Michaelidis A, Stefanadis C. Metabolic syndrome and atrial fibrillation in patients with essential hypertension. Nutr Metab Cardiovasc Dis. 2013;23(2):109-14.

16. Tanner RM, Baber U, Carson AP, Voeks J, Brown TM, Soliman EZ, Howard VJ, Muntner P. Association of the metabolic syndrome with atrial fibrillation among United States adults (from the REasons for Geographic and Racial Differences in Stroke [REGARDS] Study). Am J Cardiol. 2011;108(2):227-32.

17. Watanabe H, Tanabe N, Watanabe T, Darbar D, Roden DM, Sasaki S, Aizawa Y. Metabolic syndrome and risk of development of atrial fibrillation: the Niigata preventive medicine study. Circulation. 2008;117(10):1255-60. 
18. Chamberlain AM, Agarwal SK, Ambrose M, Folsom AR, Soliman EZ, Alonso A. Metabolic syndrome and incidence of atrial fibrillation among blacks and whites in the Atherosclerosis Risk in Communities (ARIC) Study. Am Heart J. 2010;159(5):850-6.

19. Tang RB, Gao LY, Dong JZ, Liu XH, Liu XP, Wu JH, Long DY, Yu RH, Du X, Ma CS. Metabolic syndrome in patients with atrial fibrillation in the absence of structural heart disease from a tertiary hospital in China. Chin Med J (Engl). 2009;122(22):2744-7.

20. Barrett EJ, Liu Z. The endothelial cell: an "early responder" in the development of insulin resistance. Rev Endocr Metab Disord. 2013;14(1):21-7.

21. Baron AD. Hemodynamic actions of insulin. Am J Physiol. 1994;267(2 Pt 1):E187-202.

22. Lee $\mathrm{Y}$, Cha SJ, Park JH, et al. Association between insulin resistance and risk of atrial fibrillation in non-diabetics. Eur J Prev Cardiol. 2020;27:1934-41.

23. Danne T, Nimri R, Battelino T, Bergenstal RM, KI Close, DeVries H, et al. International consensus on use of continuous glucose monitoring. Diab Care. 2017;40:1631-40.

24. Kanauchi M. A new index of insulin sensitivity obtained from the oral glucose tolerance test applicable to advanced type 2 diabetes. Diabetes Care. 2002;25:1891-2.

25 . Ho K. A critically swift response: insulin-stimulated potassium and glucose transport in skeletal muscle. Clin J Am Soc Nephrol. 2011;6(7):1513-6.

26. Graveling AJ, Frier BM. Does hypoglycaemia cause cardiovascular events? Br J Diabetes Vasc Dis. 2010;10:5-13.

27. Wright RJ, Frier BM. Vascular disease and diabetes: is hypoglycaemia an aggravating factor? Diabetes Metab Res Rev. 2008;24:353-63pmid:18461635.

28. Desouza C, Salazar H, Cheong B, Murgo J, Fonseca V. Association of hypoglycemia and cardiac ischemia: a study based on continuous monitoring. Diabetes Care. 2003;26:1485-9pmid:12716809.

29. Gerstein HC, Miller ME, Byington RP, et al. Action to Control Cardiovascular Risk in Diabetes Study Group. Effects of intensive glucose lowering in type 2 diabetes. N Engl J Med. 2008;358:2545-59].

30. Patel A, MacMahon S, Chalmers J, et al. ADVANCE Collaborative Group. Intensive blood glucose control and vascular outcomes in patients with type 2 diabetes. N Engl J Med. 2008;358:2560-72.

31. Fontes JD, Lyass A, Massaro JM, Rienstra M, Dallmeier D, Schnabel RB, Wang TJ, Vasan RS, Lubitz SA, Magnani JW, Levy D, Ellinor PT, Fox CS, Benjamin EJ. Insulin resistance and atrial fibrillation (from the Framingham Heart Study). Am J Cardiol. 2012;109(1):87-90.

32. Devereux RB, Roman MJ, Paranicas M, et al. Impact of diabetes on cardiac structure and function: the strong heart study. Circulation. 2000;101:2271-6.

33. Rutter MK, Parise H, Benjamin EJ, et al. Impact of glucose intolerance and insulin resistance on cardiac structure and function: sex-related differences in the Framingham Heart Study. Circulation. 2003;107:448-54.

34. Sundstrom J, Lind L, Nystrom N, et al. Left ventricular concentric remodeling rather than left ventricular hypertrophy is related to the insulin resistance syndrome in elderly men. Circulation. 
2000;101:2595-600.

35. DeFronzo RA, Cooke CR, Andres R, Faloona GR, Davis PJ. The effect of insulin on renal handling of sodium, potassium, calcium, and phosphate in man. J Clin Invest. 1975;55:845-55.

36. Anderson EA, Hoffman RP, Balon TW, Sinkey CA, Mark AL. Hyperinsulinemia produces both sympathetic neural activation and vasodilation in normal humans. J Clin Invest. 1991;87:2246-52.

37. Sartori M, Ceolotto G, Papparella I, et al. Effects of angiotensin II and insulin on ERK $1 / 2$ activation in fibroblasts from hypertensive patients. Am J Hypertens. 2004;17:604-10.

\section{Tables}

Please see the supplementary files section to view the tables.

\section{Figures}
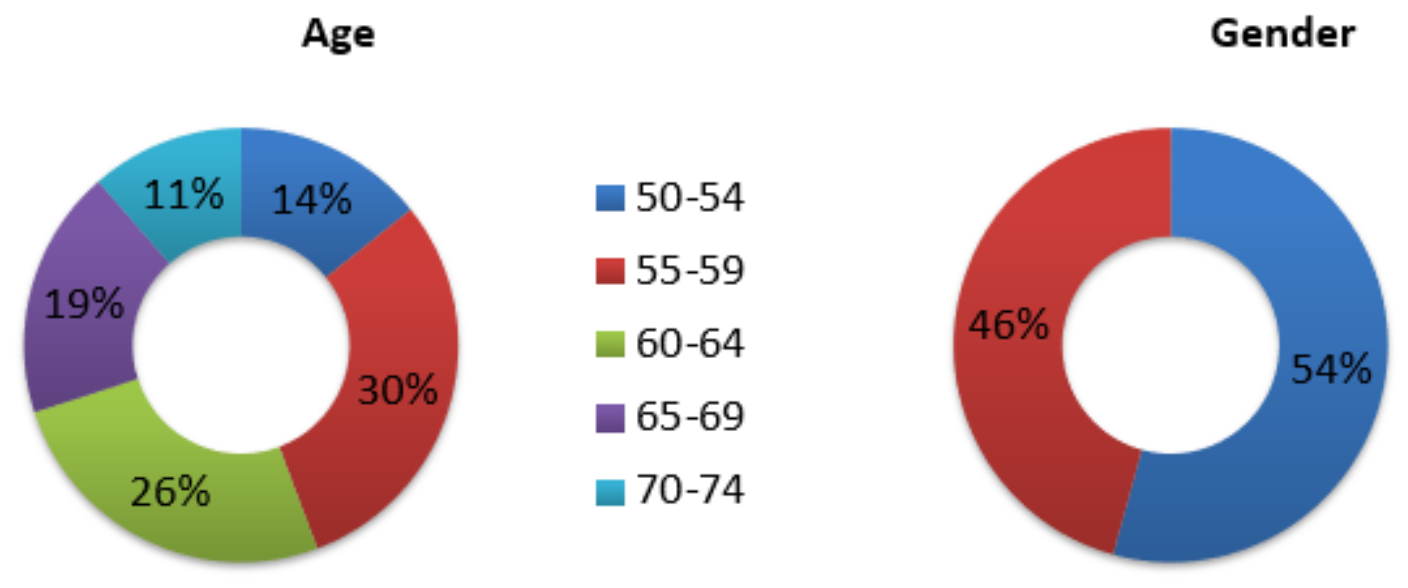

- Male

- 60-64

- 65-69

- 70-74

$50-54$
$-55-59$

- Female

Duration of diabetes

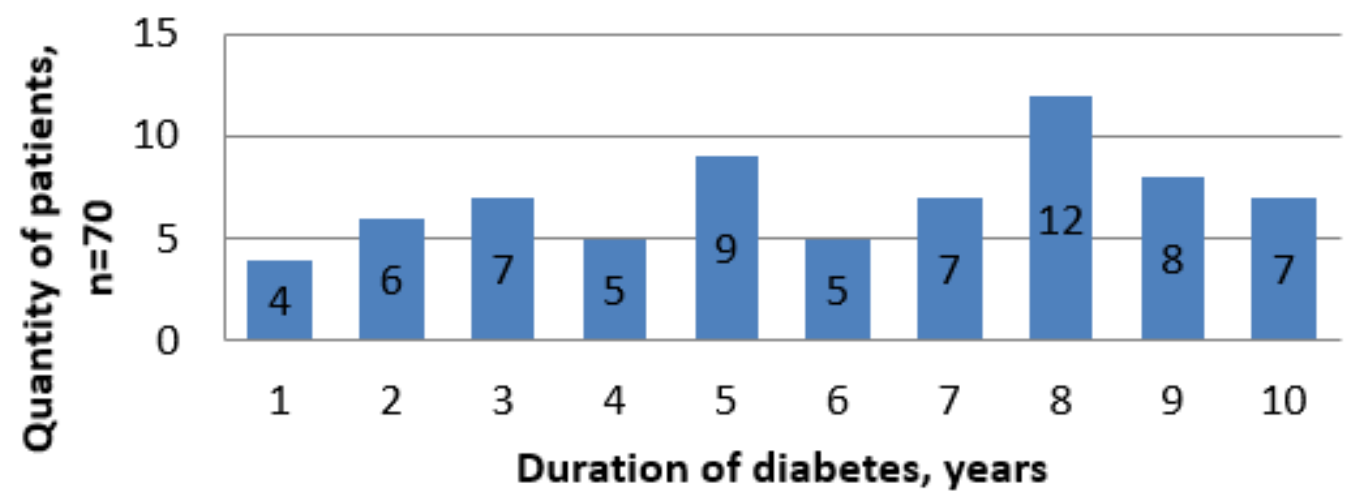

Figure 1

Demographic characteristics of the study population. 


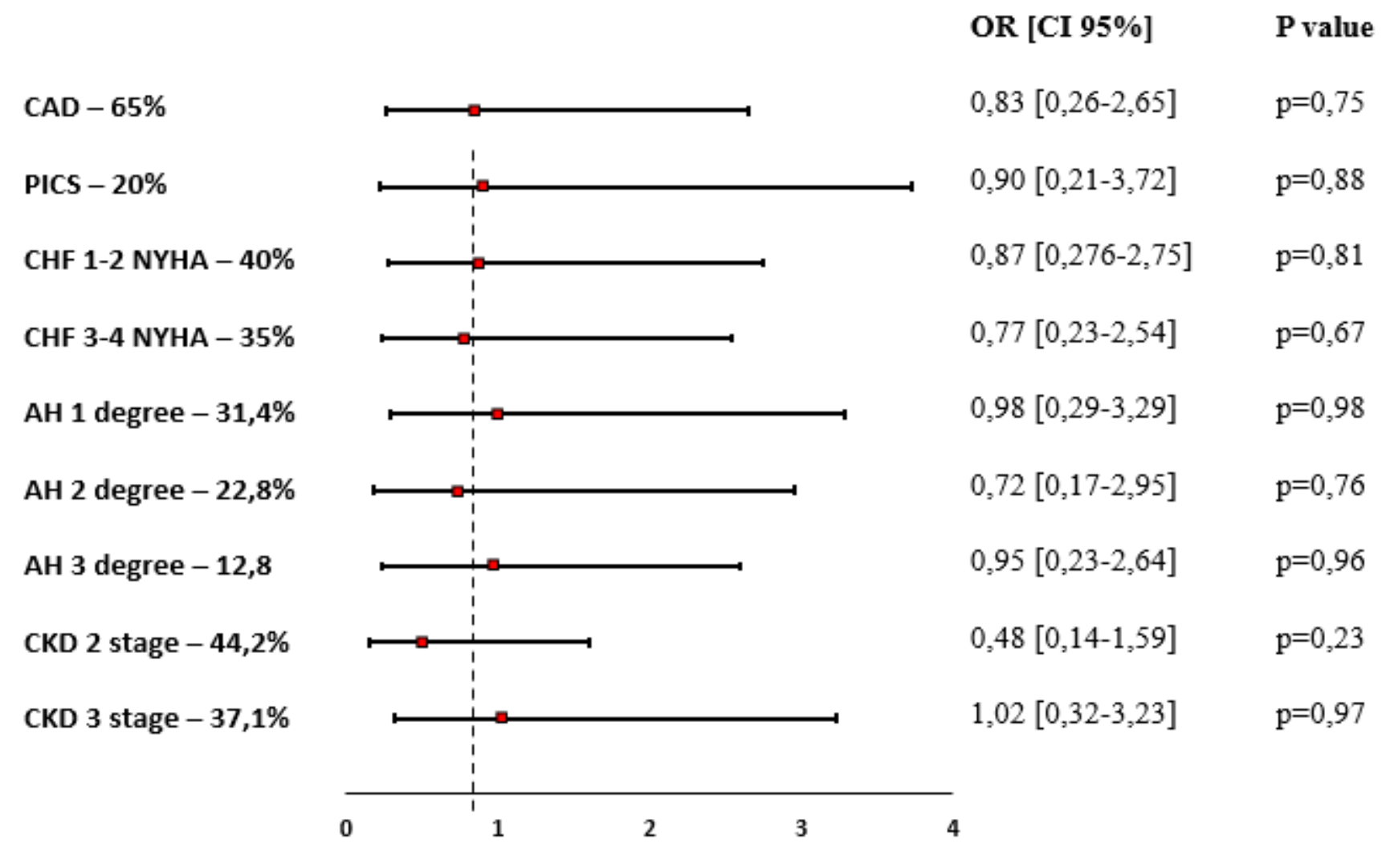

Odds ratios

\section{Figure 2}

Odds ratios (OR) and 95\% confidence interval (Cl) for the incidence of associated comorbities of atrial fibrillation and diabetes. CAD - coronary artery disease; PICS - post-infarction cardiosclerosis; CHF chronic heart failure; NYHA - New York Heart Association; AH - arterial hypertension; CKD - chronic kidney disease; $\mathrm{P}$ - significance level. 


Hypoglycemic episodes, 1 AF group
HOMA-IR index, mmol/1

Figure 3

Comparison of risk factors as hypoglycemia, insulin resistance (HOMA-IR) and fasting plasma insulin between type 2 diabetic patients who had atrial fibrillation versus none. SD - standard deviation; $\mathrm{Cl}$ confidence interval; $\mathrm{P}$ - significance level.

\section{Supplementary Files}

This is a list of supplementary files associated with this preprint. Click to download.

- Table1.pptx

- Table2.pptx

- Table3.pptx 